\title{
Noxiustoxin, A Short-Chain Toxin from the Mexican Scorpion Centruroides noxius, Induces Transmitter Release by Blocking K+ Permeability
}

\author{
María Sitges, ${ }^{*} \dagger$ Lourival Domingos Possani, ${ }^{*}$ and Alejandro Bayón ${ }^{*} \dagger$ \\ *Instituto de Investigaciones Biomédicas, Universidad Nacional Autónoma de México, México, D.F. and \\ flnstituto Mexicano de Psiquiatría, México, D.F.
}

Noxiustoxin (NTX), a 39 amino acid peptide purified from the venom of the Mexican scorpion Centruroides noxius, has been shown to block voltage-dependent $K^{+}$currents in the squid giant axon (Possani et al., 1982; Carbone et al., 1982). Although several other drugs known as $\mathrm{K}^{+}$channcl blockers in the squid axon also act on isolated nerve terminals to produce an increase in transmitter release, these releasing effects have not been shown to be related to a decrease of $\mathrm{K}^{+}$permeability in synaptosomes (Vizi et al., 1977; Tapia and Sitges, 1982). In this work we show that NTX increases ${ }^{3} \mathrm{H}$-GABA release from perfused mouse brain synaptosomes. This effect was not blocked by TTX. $\mathrm{Ca}^{2+}$ channel blockers (verapamil or $\mathrm{Co}^{2+}$ ) or the absence of external $\mathrm{Ca}^{2+}$ prevents the releasing effect of this toxin. NTX does not seem to induce transmitter release by directly increasing $\mathrm{Ca}^{2+}$ permeability: The $\mathrm{K}^{+}$ionophore valinomycin completely inhibits the release induced by NTX, as well as that evoked by the $\mathrm{K}^{+}$channel blocker 4-aminopyridine; in contrast, the release evoked by a $\mathrm{Ca}^{2+}$ ionophore is not blocked by valinomycin. These findings strongly suggest that the releasing effect of NTX is mediated by a decrease in $\mathrm{K}^{+}$permeability. External $\mathrm{Ca}^{2+}$ is needed only in order to couple this stimulus with the release process. Consistent with this hypothesis, we present evidence that NTX blocks the efflux of ${ }^{86} \mathbf{R b}^{+}$from synaptosomes. An extended comparison of the effect of 4-aminopyridine with that of NTX is also reported.

Neurotoxins from several sources, including those from scorpion venoms, have proved to be valuable tools for neurobiological studies (Catterall, 1982; Couraud and Jover, 1984; Narahashi, 1974). Recently, several toxins from the venom of the Mexican scorpion Centruroides noxius Hoffmann, have been purified and their amino acid sequences determined (Possani et al., 1981, 1982, 1985). These are basic polypeptides with a molecular weight of approximately 7000 ; some, like noxiustoxin (NTX), are short-chain polypeptides with a molecular weight of about 4000 . NTX has been studied on the voltage-clamped squid axon, in which it specifically depressed potassium permeability (Carbone et al., 1982).

Drugs like 4-aminopyridine (4-AP) and tetraethylammonium, known $\mathrm{K}^{+}$channel blockers in the squid axon, also act on nerve terminals to increase transmitter release. However, their releasing effect has not been shown to be related to a decrease in $\mathrm{K}^{+}$permeability across the synaptolema (Armstrong

Received Apr. 29, 1985; revised Oct. 22, 1985; accepted Nov. 25, 1985.

This work was supported in part by grants from CONACyT México (L.D.P., A.B.) and Fundación R. J. Zevada (B.C.H.) México.

Correspondence should be addressed to Dr. Bayón, Instituto de Investigaciones Biomédicas, Universidad Nacional Autónoma de México, Apartado Postal 70228, 04510 México, D.F., México.

Copyright (C) 1986 Society for Neuroscience $0270-6474 / 86 / 061570-05 \$ 02.00 / 0$ and Binstock, 1965; Lundh et al., 1976; Tapia and Sitges, 1982; Vizi et al., 1977; Yeh et al., 1976). Here, we show that NTX increases the release of labeled GABA from perfused mouse brain synaptosomes. We have characterized this action by studying how it is affected by the ion composition of the medium or by the presence of other drugs that modify specific ion permeabilities. Our results indicate that the releasing effect of NTX is due to a reduction of $\mathrm{K}^{+}$permeability in synaptosomes.

\section{Materials and Methods}

\section{Release experiments}

In each experiment the brains, without the cerebellums, of 4 adult albino mice (CDI strain) were used to obtain a purified synaptosomal fraction following the method of Hajós (1975) with slight modifications. The method used to load synaptosomes with labeled GABA and to study its release has been described previously (Tapia and Sitges, 1982). Briefly, aliquots ( $0.8 \mathrm{mg}$ protein) of the final synaptosomal pellet resuspended in dextrose $(0.32 \mathrm{M})$ were incubated $(10 \mathrm{~min})$ in the uptake medium (127 mM NaCl, $1.18 \mathrm{mM} \mathrm{KH}_{2} \mathrm{PO}_{4}, 3.73 \mathrm{~mm} \mathrm{KCl}, 1.8 \mathrm{mM} \mathrm{CaCl}, 1.18$ $\mathrm{mm} \mathrm{MgSO}, 20 \mathrm{~mm} \mathrm{NaHCO} 3,5.6 \mathrm{~mm}$ dextrose, aminooxyacetic acid $0.1 \mathrm{mM},{ }^{3} \mathrm{H}-\mathrm{GABA} 0.83 \mu \mathrm{Ci}, 0.5 \mu \mathrm{M}$ final concentration; the medium was bubbled with $\mathrm{O}_{2}: \mathrm{CO}_{2}, 95: 5$, to give $\mathrm{pH} 7.4$ ). ${ }^{3} \mathrm{H}-\mathrm{GABA}$-loaded synaptosomes $(0.2-0.3 \mathrm{mg}$ protein) were placed on Millipore filters $(0.65$ $\mu \mathrm{m})$ lying on perfusion chambers aligned in parallel. The uptake medium was washed out, and perfusate fractions $(0.5 \mathrm{ml})$ were collected by peristaltic pumping at $1 \mathrm{~min}$ intervals. After $6 \mathrm{~min}$ a test medium was substituted for the initial control medium. The radioactivity released into each collected fraction and that remaining in the filters at the end of the experiment was counted in Tritosol (Fricke, 1975). The release of labeled GABA per minute was expressed as the percentage of the total radioactivity present in the synaptosomes at the beginning of the perfusion (i.e., the radioactivity released during $12 \mathrm{~min}$ of perfusion plus that remaining in the filter at the end of the experiment).

Experiments to study the effect of NTX on the release (leakage) of the nontransmitter $\alpha$-amino isobutyric acid (AIB) were carried out by the same procedure as GABA, except that $2.5 \mu \mathrm{Ci}$ of ${ }^{3} \mathrm{H}$-AIB $(22 \mu \mathrm{M}$ final) was substituted for the labeled GABA in the uptake medium.

\section{Perfusion media}

The composition of standard Ringer's medium (SRM) used to perfuse the synaptosomal preparation was (mM): $\mathrm{NaCl}, 127 ; \mathrm{KH}_{2} \mathrm{PO}_{4}, 1.18$; $\mathrm{KCl}, 3.73 ; \mathrm{CaCl}_{2}, 1.8 ; \mathrm{MgSO}_{4}, 1.18 ; \mathrm{NaHCO}_{3}, 20$; dextrose, 11.2 ; and $0.1 \%$ BSA. Aminooxyacetic acid, $0.1 \mathrm{~mm}$, was present to block GABA metabolism. The final $\mathrm{pH}$ was adjusted to 7.4 by gassing the medium with $\mathrm{O}_{2}: \mathrm{CO}_{2}(95: 5, \mathrm{vol} / \mathrm{vol})$.

The GABA-releasing effect produced by NTX was first studied with regard to its dependence on the presence of external $\mathrm{Na}$ and $\mathrm{Ca}$ ions. The effect of NTX was also tested in the presence of $\mathrm{Na}^{+}$or $\mathrm{Ca}^{2+}$ channel blockers. $\mathrm{Na}^{+}$-free media were prepared by substituting $\mathrm{NaCl}$ for choline and $\mathrm{NaHCO}_{3}$ for Tris buffer, keeping the pH at 7.4. $\mathrm{Ca}^{2+}$-free media were prepared by excluding this ion from standard Ringer's and adding $50 \mu \mathrm{M}$ EGTA. TTX, $0.5 \mu \mathrm{M}$, was used to block $\mathrm{Na}^{+}$channels. In order to block $\mathrm{Ca}^{2+}$ channels, low concentrations of verapamil $(20 \mu \mathrm{M})$ or $\mathrm{Co}^{2+}$ 
$A$

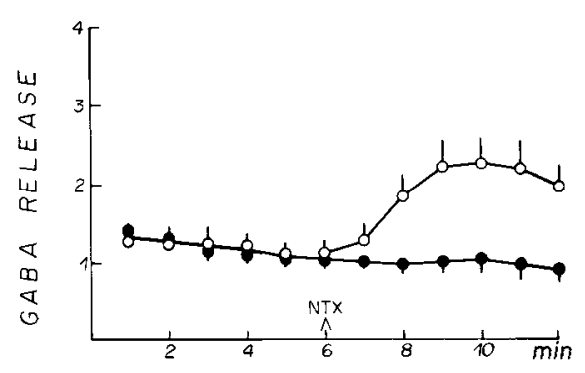

$B$
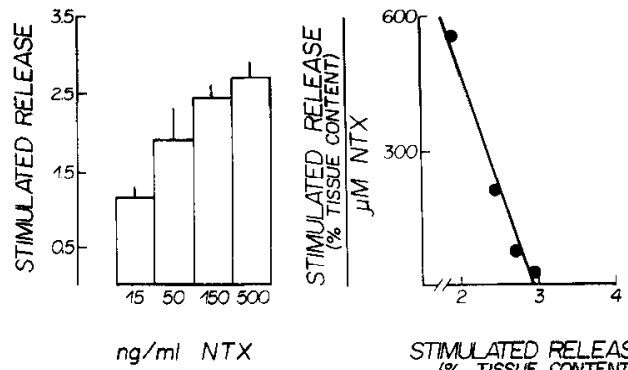

STMULATEO RELEASE
(\% TISSUE CONTENT)

Figure 1. Effect of NTX on the resting release of GABA. $A$, Synaptosomes were loaded with labeled GABA and perfused as described in Materials and Methods. At 6 min (arrow), the standard, low-potassium, Ringer's medium (SRM) was rapidly substituted by the same medium (O) or by a SRM containing $0.1 \mu \mathrm{M}$ NTX (O). ${ }^{3} \mathrm{H}-\mathrm{GABA}$ release, in this and in the following figures, is expressed as the percentage of the total radioactivity present in the synaptosomes at the beginning of the perfusion (see Materials and Methods). Results are means \pm SEM of 3 independent experiments. $B$, NTX dose-response plot. Stimulated release is expressed as the difference between the percentage total radioactivity released in the presence of NTX and in the absence of NTX. Total radioactivity refers to the total label contained in synaptosomes at the beginning of the perfusion. $C$, Scatchard plot of the stimulated release evoked by increasing concentrations (3-100 nM) of NTX. For $B$ and $C$, results are means of 4 independent experiments. SEM shown in $B$.

(replacing $\mathrm{Ca}^{2+}$ ) were present in the media. The role of $\mathrm{K}^{+}$permeability on the effect of NTX was studied using synaptosomes perfused with a SRM containing $1 \mu \mathrm{g} / \mathrm{ml}$ of the $\mathrm{K}^{+}$ionophore valinomycin. In order to compare the effect of NTX in the presence of valinomycin with the effects of the $\mathrm{K}^{+}$channel blocker 4-AP $(20 \mu \mathrm{M})$ or the $\mathrm{Ca}^{2+}$ ionophore A-23187 $(5 \mu \mathrm{M})$, these drugs were also tested in the presence of vali-
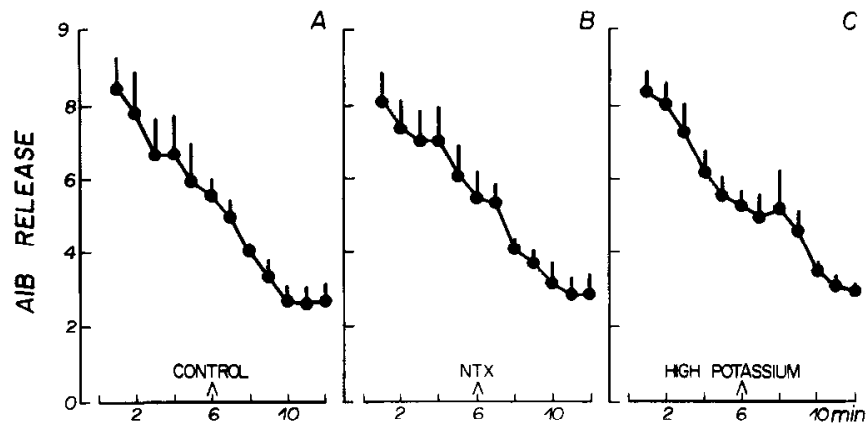

Figure 2. Passive leakage of ${ }^{3} \mathrm{H}-\mathrm{AIB}$ in the presence of NTX or high concentrations of external potassium. ${ }^{3} \mathrm{H}$-AIB-loaded synaptosomes were perfused with SRM. At 6 min (arrows), the SRM was substituted by the same medium $(A)$, by SRM containing $0.2 \mu \mathrm{M}$ NTX $(B)$, or by a 50 mM $\mathrm{K}^{+}$depolarizing medium $(C)$. Results are means \pm SEM of 4 independent experiments.

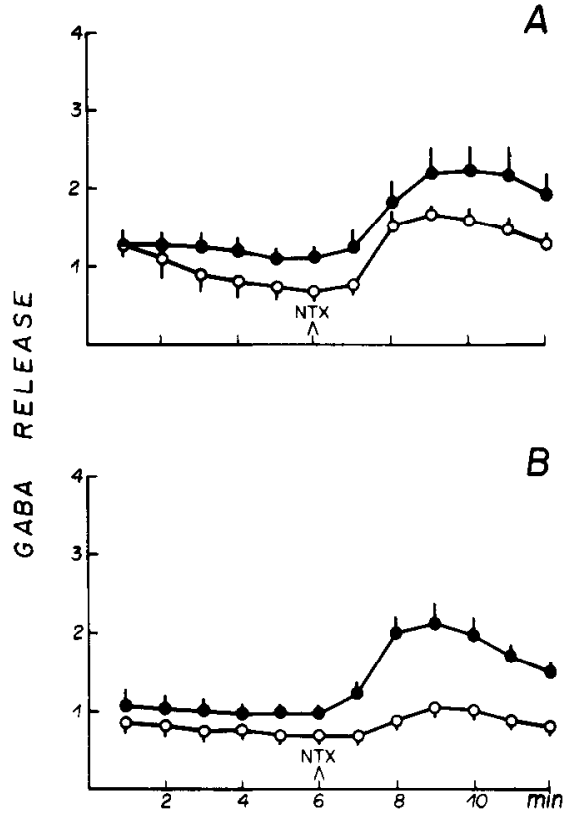

Figure 3. Release of GABA evoked by NTX in the presence of TTX and in the absence of external sodium. $A$, Synaptosomes were perfused with SRM (O) or with SRM containing $0.5 \mu \mathrm{M}$ TTX (O); NTX $(0.1 \mu \mathrm{M})$ was added to these perfusing media from min 6 (arrowhead) to min 12 . $B$, Synaptosomes were perfused with SRM (O) or with a modified SRM in which $\mathrm{Na}^{+}$was replaced by choline (O); NTX was added as indicated in $A$. Results (expressed as a percentage of ${ }^{3} \mathrm{H}-\mathrm{GABA}$ in synaptosomes before perfusion), are means \pm SEM of 3 independent experiments.

nomycin. Experiments were designed to study the combined effects of NTX and a depolarizing high-potassium $(15 \mathrm{~mm})$ perfusion medium, substituting $\mathrm{K}^{+}$for an equimolar concentration of $\mathrm{Na}^{+}$. The combined actions of NTX and veratrine $(2.5 \mu \mathrm{g} / \mathrm{ml})$ and of NTX and 4-AP (1 $\mathrm{mm}$ ) on GABA release were also studied.

\section{Rubidium efflux}

Experimental procedures were similar to those used to study the release of GABA. Synaptosomes were resuspended in SRM (2.5 mg synaptosomal protein $/ \mathrm{ml}$ ), preincubated $5 \mathrm{~min}$, and incubated in the presence of ${ }^{86} \mathrm{Rb}^{+}\left(1.5 \times 10^{6} \mathrm{cpm} / \mathrm{ml}\right)$ for $20 \mathrm{~min}$. Aliquots $(250 \mu \mathrm{l})$ from this suspension were placed in microporous filters and rapidly washed 3 times with $5 \mathrm{ml}$ of cold SRM. This preparation was perfused until a constant ${ }^{86} \mathrm{Rb}^{+}$efflux was attained, before testing the effect of NTX. Perfusate fractions were collected every $30 \mathrm{sec} .{ }^{86} \mathrm{Rb} \mathrm{b}^{+}$efflux is expressed as the percentage of the total radioactivity present in synaptosomes at the beginning of the perfusion.

NTX (fraction II-11 from the venom of C. noxius Hoffmann) was purified according to Possani et al. (1982). Other toxins from this venom, II-9.2.2 and II-10, were purified according to Possani et al. (1981). 2,3-3 $\mathrm{H}-\mathrm{GABA}$ (specific activity $34.7 \mathrm{Ci} / \mathrm{nmol}$ ) and $\alpha$-methyl- ${ }^{3} \mathrm{H}-\mathrm{AIB}$ (specific activity, $2.2 \mathrm{Ci} / \mathrm{nmol}$ ) were obtained from New England Nuclear. ${ }^{86} \mathrm{Rb}^{+}$(specific activity, $0.24 \mathrm{Ci} / \mathrm{nmol}$ ) was from Amersham. Veratrine hydrochloride, TTX, 4-AP, valinomycin, aminooxyacetic acid, and the calcium ionophore A23187 (cat. no. 7522) were from Sigma Chemical Co. (St. Louis, MO). Verapamil $\mathrm{HCl}$ was a gift of $\mathrm{Knoll}$ Laboratories (México, D.F.).

\section{Results}

\section{Effect of NTX on resting release of GABA}

Synaptosomes were perfused with SRM and then exposed to the same medium containing various concentrations of NTX. There was no observable delay in the onset of the response (Fig. 1A). A dose-dependent increase of labeled GABA release was observed. Maximal stimulation was obtained with $500 \mathrm{ng} / \mathrm{ml}$ $(0.1 \mu \mathrm{M})$ NTX (Fig. 1B); higher concentrations produced the 


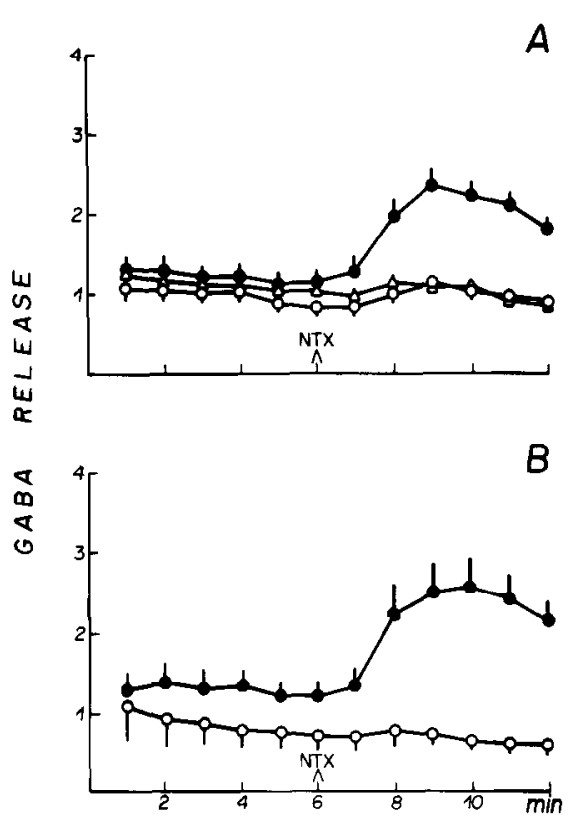

Figure 4. Inhibition of the releasing effect of NTX in the absence of external $\mathrm{Ca}^{2+}$ or in the presence of verapamil or $\mathrm{Co}^{2+}$. Synaptosomes were perfused with SRM (๑, control), SRM containing $20 \mu \mathrm{M}$ verapamil $(O$, in $A)$, SRM Ca ${ }^{2+}$-free containing $50 \mu \mathrm{M}$ EGTA $(\triangle)$, or with a SRM in which $\mathrm{Ca}^{2+}$ was replaced for $\mathrm{Co}^{2+}(\mathrm{O}$, in $B)$. In all cases, $0.1 \mu \mathrm{M}$ NTX was added at $6 \mathrm{~min}$ (arrow). Each point is the mean of 3 experiments \pm SEM.

same response. An $\mathrm{ED}_{50}$ of $2.9 \mathrm{nM}$ NTX was calculated from the Scatchard plot of the dose-response data (Fig. 1C).

Figure 2 shows that the passive leakage of a nontransmitter amino acid, AIB, from nerve terminals is not altered by the presence of NTX nor by chemical depolarization $\left(50 \mathrm{mM} \mathrm{K}^{+}\right)$.

\section{Effect of NTX in the presence of TTX and in the} absence of external $\mathrm{Na}^{+}$

Although the presence of TTX in the perfusing medium decreases the resting release of GABA, it does not affect the release evoked by NTX (Fig. $3 A$ ); nor can the absence of external Na ${ }^{+}$ completely block the NTX releasing effect (Fig. $3 B$ ).

Dependence of the effect of NTX on external $\mathrm{Ca}^{2+}$ and $\mathrm{Ca}^{2+}$ permeability

In the absence of calcium ( $50 \mu \mathrm{M}$ EGTA) in the perfusion medium, NTX did not increase the release of labeled GABA. Also, the substitution of cobalt for $\mathrm{Ca}^{2+}$ or the addition of a low concentration of verapamil $(20 \mu \mathrm{M})$ to the medium blocked the release induced by this toxin (Fig. 4).

\section{Suppression of the NTX effect by increasing $K^{+}$permeability} Although the presence of valinomycin, a $\mathrm{K}^{+}$ionophore, increases the resting GABA release, it completely blocks the release croked by NTX (Fig. 5A). Also 4-AP, a putative $\mathrm{K}^{+}$channel blocker, was ineffective in evoking release in the presence of this ionophore (Fig. $5 B$ ). In contrast, the release of GABA elicited by a calcium ionophore (A-23187) was not altered by valinomycin (Fig. 5C).

\section{Effect of NTX and 4-AP on ${ }^{86} \mathrm{Rb}^{+}$efflux}

Experiments were carried out allowing the efflux of ${ }^{86} \mathrm{Rb}^{+}$from synaptosomes to reach a steady state (10-15 min perfusion). Under this condition, addition of NTX $(0.2 \mu \mathrm{M})$ rapidly decreased $\mathrm{Rb}^{+}$efflux to less than $10 \%$ of the resting value. Also, 4-AP (200 $\mu \mathrm{M})$ drastically inhibited $\mathrm{Rb}^{+}$permeability (Fig. 6).
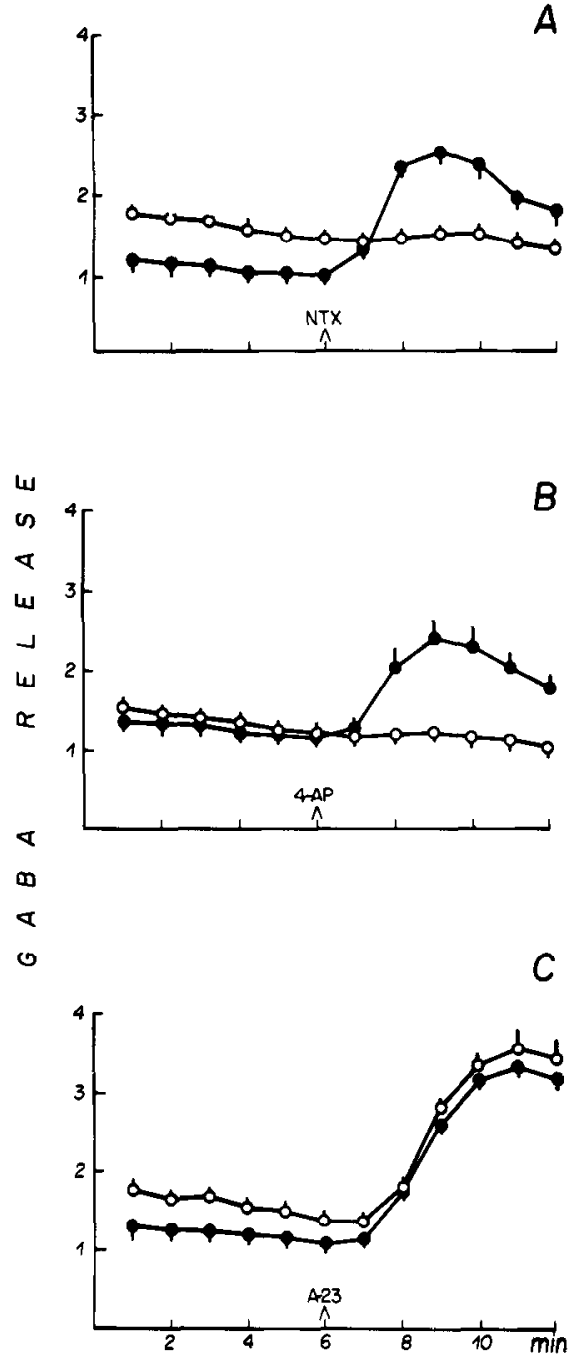

Figure 5. Modification of the release of ${ }^{~} \mathrm{H}-\mathrm{GABA}$ evoked by NTX, 4-AP, and A-23187 in the presence of the $\mathrm{K}^{+}$ionophore valinomycin. Synaptosomes were perfused with SRM (O) or with SRM containing 1 $\mu \mathrm{g} / \mathrm{ml}$ valinomycin (O). Beginning at $6 \mathrm{~min}$ these media also contained $0.1 \mu \mathrm{M}$ NTX $(A), 50 \mu \mathrm{M} 4-\mathrm{AP}(B)$, and $5 \mu \mathrm{M}$ calcium ionophore A-23187 (C). Each point is the mean of 3-4 experiments.

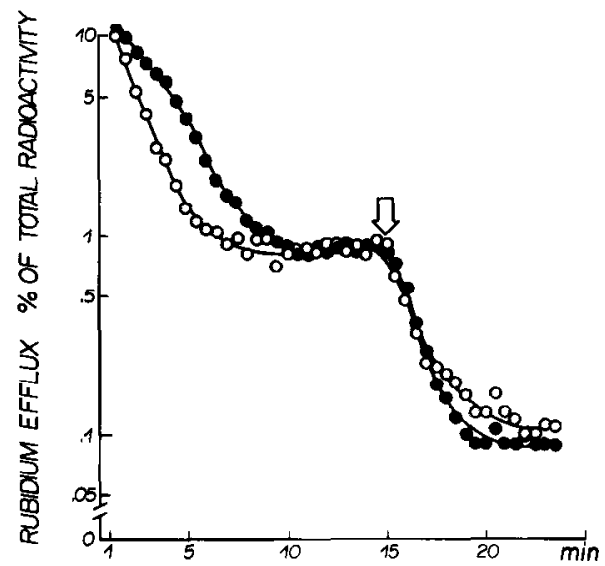

Figure 6. Effect of NTX and 4-AP on ${ }^{86} \mathrm{Rb}^{+}$efflux from synaptosomes. Filter holding ${ }^{86} \mathrm{Rb}^{+}$-loaded synaptosomes were transferred to parallel perfusion chambers and superfused with SRM. At the time indicated by the arrow, SRM was substituted by a SRM containing $0.24 \mu \mathrm{M}$ NTX (O) or $200 \mu \mathrm{M}$ 4-AP $(0)$. Results are expressed as a percentage of the total radioactivity contained in the synaptosomes. 


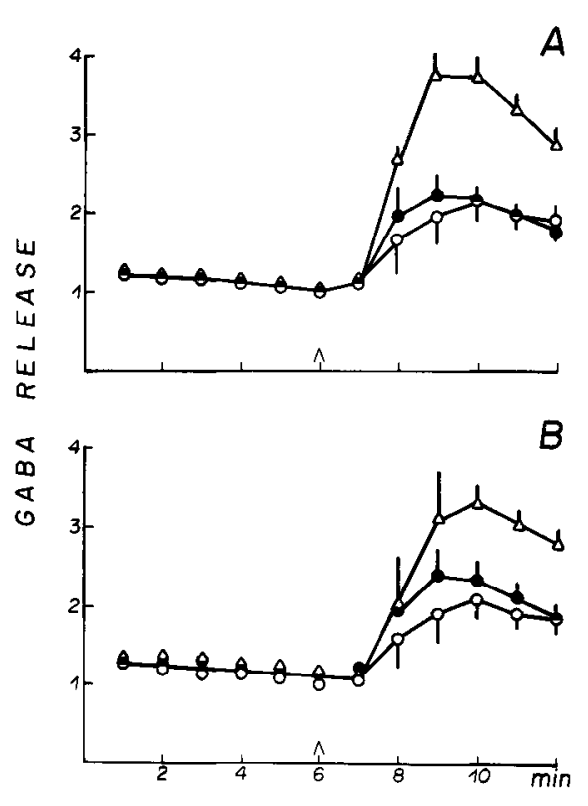

Figure 7. Combined effects of NTX or 4-AP and veratrine. Synaptosomes were perfused with the SRM, and at $6 \mathrm{~min}$ the SRM was substituted as follows: $A$, SRM containing $0.1 \mu \mathrm{M}$ NTX (O), SRM containing $2.5 \mu \mathrm{g} / \mathrm{ml}$ veratrine $(O)$, or SRM containing $0.1 \mu \mathrm{M}$ NTX plus $2.5 \mu \mathrm{g} / \mathrm{ml}$ veratrine $(\Delta) . B$, SRM containing $20 \mu \mathrm{M}$ 4-AP (O), SRM containing $2.5 \mu \mathrm{g} / \mathrm{ml}$ veratrine (O), or SRM containing $20 \mu \mathrm{M} 4-A P$ plus $2.5 \mu \mathrm{g} / \mathrm{ml}$ veratrine $(\Delta)$. Results are means \pm SEM of 3 independent experiments.

Independent experiments were carried out as a control of the spontaneous release of ${ }^{86} \mathrm{Rb}^{+}$for as long as $30 \mathrm{~min}$. The plateau after 10 min remained, showing that the effects of NTX or 4-AP were not artifactual (data not shown).

\section{Combined effects of NTX and veratrine}

At doses of NTX and veratrine producing nearly half-maximal effects, their combined actions elicited a releasing response close to the sum of their separate contributions (Fig. 7A). Similarly, an additive effect was observed between 4-AP and veratrine (Fig. $7 B$ ). When these experiments were performed using doses of veratrine evoking the maximal response, NTX or 4-AP did not further increase the stimulated release of GABA (data not shown).

\section{Combined effects of NTX and 4-AP}

When NTX and 4-AP were tested at doses producing maximal effects, the release of GABA evoked by 4-AP was higher than that evoked by NTX. Their combined maximal effects were not additive: The release of GABA in the presence of both was

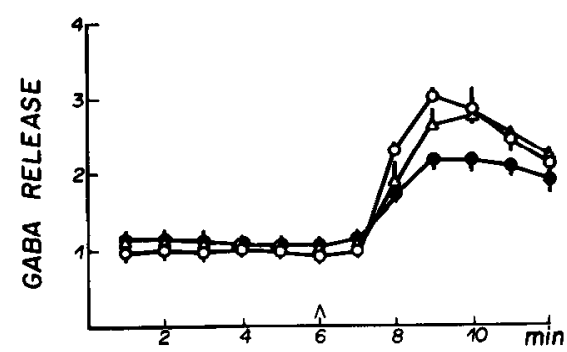

Figure 8. Combined effects of NTX and 4-AP on ${ }^{3} \mathrm{H}-\mathrm{GABA}$ release. Synaptosomes were perfused with the SRM, and at $6 \mathrm{~min}$ it was substituted by a SRM containing $0.2 \mu \mathrm{M}$ NTX (O), $1 \mathrm{mM}$ 4-AP (O), or NTX plus 4-AP at the indicated concentrations $(\triangle)$. Each point is the mean \pm SEM of 3 independent experiments.

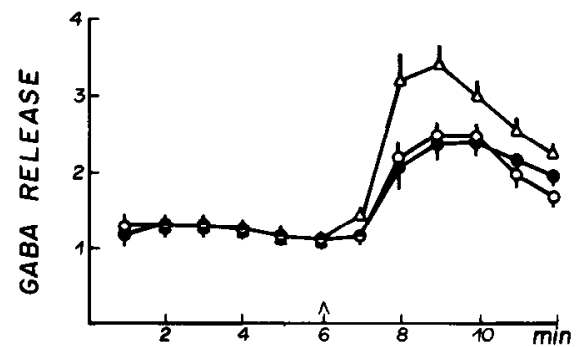

Figure 9. Combined effects of NTX and high $\mathrm{K}^{+}(15 \mathrm{~mm})$ on ${ }^{3} \mathrm{H}$ GABA release. Synaptosomes were perfused with the SRM, and at 6 min SRM was substituted by SRM containing $0.1 \mu \mathrm{M}$ NTX (O); SRM containing $15 \mathrm{~mm} \mathrm{~K} \mathrm{~K}^{+}(\mathrm{O})$, or $15 \mathrm{mM} \mathrm{K}+$ Ringer's containing $0.1 \mu \mathrm{M}$ NTX $(\triangle)$. Each point is the mean \pm SEM of 3 experiments.

between that produced by NTX or 4-AP alone (Fig. 8). At lower 4-AP doses, the combined action of NTX and 4-AP always resulted in a releasing response, lower than that evoked by 4-AP alone (data not shown).

\section{Effect of NTX in the presence of high concentrations of external potassium}

The effect of NTX on chemically depolarized synaptosomes was studied by adding this toxin to a perfusing medium containing $15 \mathrm{mM} \mathrm{K}^{+}$. The releasing effect of NTX $(0.1 \mu \mathrm{M})$ was superimposed on that produced by the depolarizing medium (Fig. 9). Synaptosomes depolarized in $50 \mathrm{~mm}$ external $\mathrm{K}^{+}$released 6 times more ${ }^{3} \mathrm{H}-\mathrm{GABA}$ than $15 \mathrm{~mm} \mathrm{~K}^{+}$or NTX alone, and the addition of NTX did not further increase this release (data not shown).

\section{Discussion}

We have shown that the exposure of synaptosomes to NTX purified from $C$. noxius venom results in an enhanced release of preloaded labeled neurotransmitter. In contrast, NTX did not increase the release of the nontransmitter amino acid ${ }^{3} \mathrm{H}$ AIB. This difference shows that NTX acts on the physiological mechanisms involved in neurotransmitter release and does not have an indiscriminate effect promoting the leakage of synaptosomal contents. It is noteworthy that the effective doses of NTX in the axon $\left(K_{\mathrm{d}}=300 \mathrm{nM}\right)$ (Carbonc ct al., 1982) and in synaptosomes $\left(\mathrm{ED}_{50}=2.9 \mathrm{nM}\right)$ differ widely. In addition, the delay of several min to the onset of NTX action on the squid axon was not observed in the synaptosomal preparation. These differences could be explained by a difference in the access of NTX to its receptors in each of these preparations.

The releasing effects of many scorpion toxins, including some from $C$. noxius (Table 1), are mediated by an increase of $\mathrm{Na}^{+}$ permeability that is blocked by TTX. The results given in Table 1 show that toxins II-9.2.2 and II-10, both long-chain toxins

Table 1. GABA release evoked by $C$. noxius toxins in the presence of TTX or veratrine

\begin{tabular}{lccc} 
& \multicolumn{3}{l}{ Evoked release (\%) } \\
\cline { 2 - 4 } Scorpion toxins & $\begin{array}{l}\text { NTX } \\
(0.1 \mu \mathrm{M})\end{array}$ & $\begin{array}{l}\text { II-9.2.2 } \\
(0.2 \mu \mathrm{M})\end{array}$ & $\begin{array}{l}\text { II-10 } \\
(0.2 \mu \mathrm{M})\end{array}$ \\
\hline ScTx alone & $92 \pm 11^{b}$ & $92 \pm 14$ & $111 \pm 21$ \\
ScTx + TTX $(0.5 \mu \mathrm{M})$ & $89 \pm 22$ & 0 & $9 \pm 3$ \\
ScTx + veratrine & & & \\
$\quad(2.5 \mu \mathrm{g} / \mathrm{ml})(71 \pm 11)$ & $183 \pm 15$ & $297 \pm 32$ & $298 \pm 31$
\end{tabular}

Evoked release is expressed as a percentage of the resting control values. a Scorpion toxins (ScTX) were tested either alone or together with TTX or veratrine. Veratrine $(2.5 \mu \mathrm{g} / \mathrm{ml})$ alone stimulated release by $71 \pm 11 \%$, and TTX alone slightly decreased $(30 \pm 6 \%)$ the resting value.

${ }^{b}$ SEM calculated from 3-4 independent experiments. 
from $C$. noxius venom, affect GABA release from synaptosomes in a similar way as those from Tityus serrulatus and C. suffusus suffisus (Couraud et al., 1982; Coutinho-Netto et al., 1980). In contrast, the effect of NTX was not blocked by TTX, indicating that NTX does not induce GABA release through the activation of TTX-sensitive $\mathrm{Na}^{+}$channels. However, the releasing action of NTX appeared to depend on the sodium gradient and the sodium equilibrium potential, which are reversed in $\mathrm{Na}^{+}$-free media, since the absence of external $\mathrm{Na}^{+}$reduced the effectiveness of NTX.

The release of GABA induced by NTX was blocked in the absence of external $\mathrm{Ca}^{2+}$ or by the presence of $\mathrm{Ca}^{2+}$ channel antagonists. This observation indicated that $\mathrm{a} \mathrm{Ca}^{2+}$ influx through verapamil or cobalt-sensitive $\mathrm{Ca}^{2+}$ channels might be directly induced by the toxin or otherwise required for the release process triggered by NTX.

The latter possibility - that NTX can initiate the release process by a mechanism different from direct activation of $\mathrm{Ca}^{2+}$ channels-is supported by the fact that this toxin decreases $\mathrm{K}^{+}$ permeability in the voltage-clamped squid axon (Carbone et al., 1982). In order to test if the release of GABA evoked by NTX was triggered by a rcduction of $\mathrm{K}^{+}$permeability, synaptosomes were treated with valinomycin to increase their permeability to $\mathrm{K}^{+}$ions. In the presence of this $\mathrm{K}^{+}$ionophore, the releasing action of NTX was completely blocked. Also, the release of GABA evoked by 4-AP, a drug that blocks the $\mathrm{K}^{+}$conductance in the presynaptic terminal of the squid giant synapse (Llinas et al., 1976), was inhibited by valinomycin. In contrast, the release evoked by a calcium ionophore was not modified in the presence of valinomycin, making it unlikely that NTX could act by directly increasing $\mathrm{Ca}^{2+}$ permeability. Thus, the $\mathrm{Ca}^{2+}$ dependence of the releasing effect of NTX appears to be linked to the role of this ion in the coupling of stimulus and secretion. All these results, along with direct evidence that NTX (and also 4-AP) blocks ${ }^{86} \mathrm{Rb}$ efflux in the synaptosomal preparation, support the concept that this toxin induces release by decreasing $\mathrm{K}^{+}$permeability.

The effect of many scorpion toxins that bind to $\mathrm{Na}^{+}$channels is potentiated in the presence of steroidal alkaloids like veratridine, which are also activators of $\mathrm{Na}^{+}$currents (Catterall, 1975; Krueger and Blaustein, 1980; Ulbricht, 1969). Neither the releasing effect of NTX nor that of 4-AP was potentiated by veratrine, further supporting the concept that the mechanism of action of NTX differs from that of the scorpion toxins acting on $\mathrm{Na}^{+}$channels (Table 1). However, the observation that the effects of NTX and veratrine appear to be additive suggests that stimuli mediated through $\mathrm{K}^{+}$and $\mathrm{Na}^{+}$channels are capable of acting simultaneously to increase transmitter release.

Although NTX and 4-AP behave as $\mathrm{K}^{+}$channel blockers, several differences between them have been found. The maximal releasing response evoked in their presence differs, suggesting that they might preferentially interact with different populations of $\mathrm{K}^{+}$channels (Bartschat and Blaustein, 1985; Rogawski, 1985) or that they could use different mechanisms to reduce $\mathrm{K}^{+}$permeability. In this regard it is noteworthy that the combined effect of NTX and 4-AP that we observed can be interpreted either as negative cooperativity between them or as competition for the same sites.

In the squid axon, NTX blocks $\mathrm{K}^{+}$permeability in a voltageindependent manner (Carbone et al., 1982), whereas the blockade produced by 4-AP is overcome at large depolarizations (Yeh et al., 1976). Consistent with this observation is the finding that while 4-AP is unable to increase the release of transmitters in a depolarized ( $20 \mathrm{mM} \mathrm{K}^{+}$) synaptosomal preparation (Tapia and Sitges, 1982), NTX-induced release is observed over and above that produced by $15 \mathrm{~mm}$ external $\mathrm{K}^{+}$.

Finally, among $\mathrm{K}^{+}$channel blockers, NTX is the most potent: In synaptosomes the $\mathrm{ED}_{s 0}$ of NTX-induced GABA release is
$2.9 \mathrm{nM}$, while 4-AP is required in micromolar concentrations to elicit a measurable release (Tapia and Sitges, 1982). In the squid axon, NTX has a $K_{\mathrm{d}}$ of 300 nM to depress $\mathrm{K}^{+}$permeability (Carbone et al., 1982), whereas 4-AP and TEA are active only in the millimolar range (Armstrong and Binstock, 1965; Yeh et al., 1976).

NTX actions have to be characterized in more detail using other techniques and preparations, but what we know about its mechanism of action on the nerve terminals makes it a promising tool for neurobiological research.

\section{References}

Armstrong, C. M., and L. Binstock (1965) Anomalous rectification in the squid giant axon injected with tetraethylammonium chloride. $J$. Gen. Physiol. 48: 859-872.

Bartschat, D. K., and M. P. Blaustein (1985) Calcium-activated potassium channels in isolated presynaptic nerve terminals from rat brain. J. Physiol. (Lond.) 361: 441-457.

Carbone, E., E. Wanke, G. Prestipino, L. D. Possani, and A. Maelicke (1982) Selective blockage of voltage-dependent $\mathrm{K}^{+}$channels by a novel scorpion toxin. Nature 296: 90-91.

Catterall, W. A. (1975) Cooperative activation of action potential $\mathrm{Na}^{+}$ ionophore by neurotoxins. Proc. Natl. Acad. Sci. USA 72: 17821786.

Catterall, W. A. (1982) The emerging molecular view of the sodium channel. Trends Neurosci. 5: 303-305.

Couraud, F., and E. Jover (1984) Mechanism of action of scorpion toxins. In Handbook of Natural Toxins, Vol. 2, A. T. Tu, ed., pp. 659-678, Dekker, New York.

Couraud, F., E. Jover, J. M. Dubois, and H. Rochat (1982) Two types of scorpion toxin receptor sites, one related to the activation, the other to the inactivation of the action potential sodium channel. Toxicon 20: 9-16.

Coutinho-Netto, J., A. S. Abdul-Ghani, P. J. Norris, A. J. Thomas, and H. F. Bradford (1980) The effects of scorpion venom toxin on the release of amino acid neurotransmitters from cerebral cortex in vivo and in vitro. J. Neurochem. 35: 558-565.

Fricke, U. (1975) Tritosol: A new scintillation cocktail based on Triton-X-100. Anal. Biochem. 63: 555-558.

Hajós, F. (1975) An improved method for the preparation of synaptosomal fractions in high purity. Brain Res. 93: 485-489.

Krueger, B. K., and M. P. Blaustein (1980) Sodium channels in presynaptic nerve terminals. J. Gen. Physiol. 76: 287-313.

Llinás, R., K. Walton, and V. Bohr (1976) Synaptic transmission in the squid giant synapse after potassium conductance blockade with external 3- and 4-aminopyridine. Biophys. J. 16: 83-86.

Lundh, H., S. G. Cull Candy, S. Leander, and S. Thesleff (1976) Restoration of transmitter release in botulinium poisoned skeletal muscle. Brain Res. 110: 194-198.

Narahashi, T. (1974) Chemicals as tools in the study of excitable membranes. Physiol. Rev. 54: 813 .

Possani, L. D., M. A. R. Dent, B. M. Martin, A. Maelicke, and I. Svendsen (1981) The amino terminal sequence of several toxins from the venom of the Mexican scorpion Centruroides noxius Hoffmann. Carlsberg Res. Commun. 46: 207-214.

Possani, L. D., B. M. Martin, and I. Svendsen (1982) The primary structure of noxiustoxin: $\mathrm{A} \mathrm{K}^{+}$channel blocking peptide, purified from the venom of the scorpion Centruroides noxius Hoffmann. Carlsberg Res. Commun. 47: 285-289.

Possani, L. D., B. M. Martin, I. Svendsen, G. S. Rode, and B. W. Erickson (1985) Scorpion toxins from Centruroides noxius and Tityus serrulatus. J. Biochem. 229: 739-750.

Rogawski, M. A. (1985) The A-current: How ubiquitous a feature of excitable cells is it? Trends Neurosci. 8: 214-219.

Tapia, R., and M. Sitges (1982) Effect of 4-aminopyridine on transmitter release in synaptosomes. Brain Res. 250: 291-299.

Ulbricht, W. (1969) The effect of veratridine on excitable membranes of nerve and muscle. Ergeb. Physiol. Biol. Chem. Exp. Pharmakol. 61: 18-71.

Vizi, E. S., J. Van Dijk, and F. F. Foldes (1977) Effect of 4-aminopyridine on acetylcholine release. J. Neural Transm. 41:265-274.

Yeh, J. Z., G. S. Oxford, C. H. Wu, and T. Narahashi (1976) Interactions of aminopyridines with potassium channels of squid axon membranes. Biophys. J. 16: 77-81. 